\title{
RESEARCH
}

Open Access

\section{How is equity approached in universal health coverage? An analysis of global and country policy documents in Benin and Senegal}

Elisabeth Paul ${ }^{1,2^{*}}$ (D) Céline Deville ${ }^{1}$, Oriane Bodson ${ }^{1}, N^{\prime}$ koué Emmanuel Sambiéni ${ }^{3}$, Ibrahima Thiam4, Marc Bourgeois ${ }^{5}$, Valéry Ridde ${ }^{6}$ and Fabienne Fecher $^{1}$

\begin{abstract}
Background: Equity seems inherent to the pursuance of universal health coverage (UHC), but it is not a natural consequence of it. We explore how the multidimensional concept of equity has been approached in key global UHC policy documents, as well as in country-level UHC policies.
\end{abstract}

Methods: We analysed a purposeful sample of UHC reports and policy documents both at global level and in two Western African countries (Benin and Senegal). We manually searched each document for its use and discussion of equity and related terms. The content was summarised and thematically analysed, in order to comprehend how these concepts were understood in the documents. We distinguished between the level at which inequity takes place and the origin or types of inequities.

Results: Most of the documents analysed do not define equity in the first place, and speak about "health inequities" in the broad sense, without mentioning the dimension or type of inequity considered. Some dimensions of equity are ambiguous - especially coverage and financing. Many documents assimilate equity to an overall objective or guiding principle closely associated to UHC. The concept of equity is also often linked to other concepts and values (social justice, inclusion, solidarity, human rights - but also to efficiency and sustainability). Regarding the levels of equity most often considered, access (availability, coverage, provision) is the most often quoted dimension, followed by financial protection. Regarding the types of equity considered, those most referred to are socio-economic, geographic, and gender-based disparities. In Benin and Senegal, geographic inequities are mostly pinpointed by UHC policy documents, but concrete interventions mostly target the poor. Overall, the UHC policy of both countries are quite similar in terms of their approach to equity.

Conclusions: While equity is widely referred to in global and country-specific UHC policy documents, its multiple dimensions results in a rather rhetorical utilisation of the concept. Whereas equity covers various levels and types, many global UHC documents fail to define it properly and to comprehend the breadth of the concept. Consequently, perhaps, country-specific policy documents also use equity as a rhetoric principle, without sufficient consideration for concrete ways for implementation.

Keywords: Universal health coverage, Equity, Global reports, Policy documents, Low- and middle-income countries, Benin, Senegal

\footnotetext{
* Correspondence: E.Paul@uliege.be

1 Université de Liège, Faculty of Social Sciences, Place des Orateurs 3, 4000

Liège, Belgium

${ }^{2}$ Université libre de Bruxelles, School of Public Health, Campus Erasme, Route

de Lennik 808, 1070 Brussels, CP 591, Belgium

Full list of author information is available at the end of the article
}

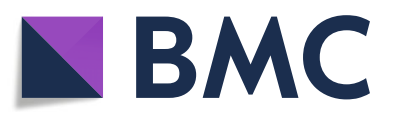

(c) The Author(s). 2019 Open Access This article is distributed under the terms of the Creative Commons Attribution 4.0 International License (http://creativecommons.org/licenses/by/4.0/), which permits unrestricted use, distribution, and reproduction in any medium, provided you give appropriate credit to the original author(s) and the source, provide a link to the Creative Commons license, and indicate if changes were made. The Creative Commons Public Domain Dedication waiver (http://creativecommons.org/publicdomain/zero/1.0/) applies to the data made available in this article, unless otherwise stated. 


\section{Background}

Universal health coverage (UHC) means that all people receive the health services they need, including health initiatives designed to promote better health, prevent illness, and to provide the treatment, rehabilitation and palliative care of sufficient quality to be effective while at the same time ensuring that the use of these services does not expose the user to financial hardship [1]. Equity seems inherent to the pursuance of UHC: for instance, the World Health Report 2008 defines universal coverage reforms as "reforms that ensure that health systems contribute to health equity, social justice and the end of exclusion, primarily by moving towards universal access and social health protection" [2]; the World Health Organisation (WHO) believes that equity is an intermediate objective of UHC [3]; and the WHO Consultative Group on Equity and Universal Health Coverage urges countries to commit to fairness, equity and rights to health in policymaking [4]. However, equity is not a natural consequence of the implementation of UHC policies. On the contrary, the pursuance of UHC implies trade-offs which are not necessarily favourable to vulnerable people, and some policies pursued in the name of UHC may worsen inequalities [5-8]. Hence the acknowledged importance of measuring inequity, and tracking progress in this regard when implementing UHC policies $[9,10]$.

Note first that equity is a commonly used term in public health. A narrative review of peer-reviewed literature published in English between 2005 and 2013 retrieved approximately 9000 papers from PubMed via the search words, 'universal health coverage/care' and 'equity/inequity' [9]. However, it is a controversial, ambiguous concept that is intertwined with a number of other concepts such as fairness (which is a broader concept and specifically focuses on the worst-off), equality, social justice, social inclusion, solidarity, altruism, and rights to health $[4,6,11-15]$. It is opposed to health inequalities or disparities, which refer to health differences that are avoidable, unnecessary, and unjust [16]. Health inequities are also closely interconnected with disparities in social determinants of health [17].

Equity in health encompasses various dimensions, some related to means or processes, some related to ends or outcomes [13]: equity in healthcare coverage (access, use of services) (often called horizontal equity: equal treatment for equal need); equity in health outcomes; equity in health financing (often called vertical equity, meaning that everyone contributes to health financing according to one's ability to pay); equity in financial protection. When associated to the pursuance of UHC, studies from lowand middle-income countries generally explore the equity impact of UHC based on disaggregated data by geographical area, socio-economic status and gender; but another key area in which inequity may arise across both developing and developed contexts is disparities in the quality of care and access to specialised clinical services [9]. Other types of disparities in health services relate to race/ethnicity, culture, education, or other social advantages [17-21]. The measurement of health inequalities remains challenging and is an evolving concept $[9,12,22-25]$.

\section{Methods}

This paper aims to explore on the one hand how the multidimensional concept of equity has been approached in key global UHC reports and policy documents, and on the other hand whether and how this understanding impacts on UHC policies at country level. To do so, we analysed a sample of key UHC reports and policy document both at the global level and in two countries: Benin and Senegal. These two countries are the focus of our research project (2015-2019) on UHC policies. They are located in Francophone Western Africa, have relatively similar health systems and challenges, but have chosen very different paths to expand financial protection coverage for healthcare: while Senegal has opted for communitybased health insurance (CBHI), Benin is striving to develop a national, state-led health insurance [26]. This offers interesting comparisons.

We used a similar heuristic approach to the one used by other authors regarding quality in health systems policy [27], and searched the websites of the two major global institutions shaping UHC policies and in charge of its global monitoring - the WHO and the World Bank (WB) - for reports and policy documents dedicated to UHC. We selected the most relevant and significant ones to build a purposeful sample of 20 key UHC reports and policy documents issued after the release of the first World Health Assembly Resolution on UHC (58.33) in 2005 (actually starting in 2008) and until 2018. Note that we excluded two documents whose primary focus was to comprehend equity - the report of the Commission on social determinants of health [17], and the WB's database of equity indicators [28] - but we also identified and included a report of the International Labour Organisation (ILO) dedicated to social protection in health [29]. We manually searched each document for its use and discussion of "equit", "inequal", "unequal", and "disparit"". The content was then summarised and analysed, especially in order to understand how these concepts were comprehended in each document and to appraise the extent to which the documents were preoccupied by those concepts. This was done through a mixed approach comprising a qualitative content analysis component (thematic analysis of the discourse utilised to approach equity in the documents) and a quantitative component (counting the number of occurrences of the terms related to equity in each document, as 
well as the breadth of its understanding - levels and types of equity referred to). We distinguished between (i) the level at which inequity takes place (social determinants, health outcomes, health systems and policies, access/ coverage/use of health services, funding, and financial protection), and (ii) the origin or types of health inequities (socio-economic, gender-based, etc.). Then, we adopted the same approach to analyse how the concept of equity was comprehended in three types of UHC policy documents in Benin and Senegal: (i) the national health sector plan (NHSP), (ii) the national health financing strategies (NHFS) for UHC; and (iii) other policy documents describing the UHC strategy or scheme favoured by the government. The results are presented in summary tables and the most salient features are then explained more into details.

\section{Results}

\section{Equity in key global UHC reports and policy documents}

Table 1 offers a quantitative overview of the importance given to equity, and of the dimensions comprehended, in key global UHC policy documents.

Regarding the levels of equity most often considered, access (availability, coverage, provision, use) is the most often quoted dimension (explicitly referred to by 18 documents out of 20), followed by equity in financial protection (14/20 documents), and then equity at the level of health systems, policies and/or distribution of resources (13/20 documents), with varying focus according to sources. Other dimensions include equity in financial contribution (funding), in health outcomes, and in social determinants of health (incl. distribution of power, money and resources; health behaviours; water and sanitation). Regarding the types of equity considered, those most referred to are socioeconomic (wealth/income disparities) (explicitly referred to by 15 documents out of 20), geographic (across regions and urban/rural areas) (mentioned by 13/20 documents), other or undefined socio-economic disparities (12/20 documents), and gender-based disparities (10/20 documents). A variety of other criteria ("stratifiers") are mentioned throughout the documents: education, age, and cultural factors such as religion, race/ethnicity, and migrant status.

A more in-depth and qualitative content analysis of how equity has been approached in global UHC documents is provided in Table 2.

Analysis of that sample of key UHC policy documents offer a number of interesting comments. First, most documents $(15 / 20)$ do not define equity in the first place. Second, most documents speak about "health equity" or "inequity in health" in the broad sense, without mentioning the dimension or type of inequity considered. Third, there is a certain ambiguity in some dimensions of equity: "coverage" is sometimes utilised in the sense of access or availability of health services, sometimes in the sense of utilisation of health services; and "financing" sometimes refers to equity in funding (mobilisation of resources, vertical equity, public spending), sometimes to equity in resource allocation, and even sometimes in financial protection. Fourth, most documents assimilate equity to an overall objective or guiding principle closely associated to UHC and the Sustainable Development Goals (SDGs). However, the links alluded to between UHC and equity are not straightforward: overall, it is unclear whether a focus on equity is supposed to enable progress in UHC (equity as a means), whether UHC is supposed to increase equity (equity as an end), or whether these are two distinct aims. Similarly, it is unclear whether equity is a value or principle orienting actions, or whether it is an objective of such actions. Some of the documents try and clarify the links between UHC and equity: for instance, the publications from the health financing department of the $\mathrm{WHO}$ recurrently use a model stating that equity in the distribution of resources is a UHC intermediate objective, and equity in service use is a UHC goal $[39,45]$; a joint report views UHC as "the response to" inequities [36]; and the 2017 Global monitoring report makes a clear distinction between equity and UHC [43]. Nevertheless, the global picture is unclear in most documents, and the approach of equity is often more rhetorical than concrete. Fifth, the concept of equity is also often linked to other concepts and values such as social justice (or inclusion), solidarity, human rights (including the right to health), and poverty alleviation - but it is even more often associated with efficiency, as well as with sustainability.

\section{Implications on country UHC policies}

Table 3 and Table 4 follow a similar thematic analytical approach and summarise the results from the analysis on how the concept of equity was comprehended in three types of country-specific policy documents in Benin and Senegal: (i) the national health sector plan (NHSP), (ii) the national health financing strategy (NHFS); and (iii) other UHC policy documents.

The documents from the two countries present similarities, which enables a joint analysis. Note first that a number of findings are similar to those of the global documents. Most country-specific policy documents (7 out of 8) do not define equity in the first place; coverage, access and supply of services are used interchangeably, and the dimensions and types of health equity are often not well explicated. Regarding the level of equity considered, all country documents in our sample explicitly refer to access / coverage / use of services. Country documents also put a lot of emphasis on improving equity in allocation of resources (especially human resources) across regions (referred to explicitly by 5 documents out of 8 ), and on funding/financial contribution (5/8 as well). Regarding the types of equity considered, undefined or 


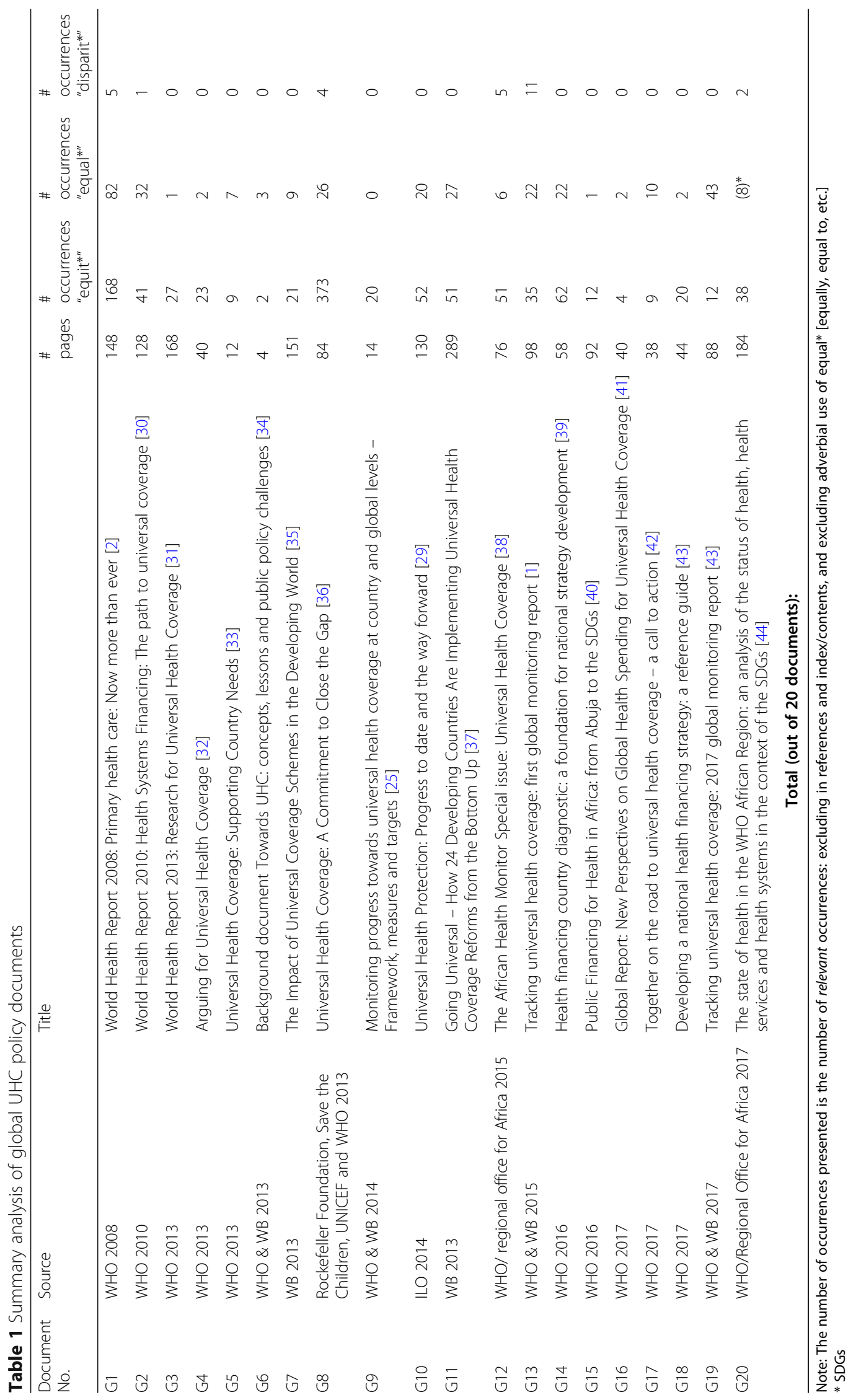




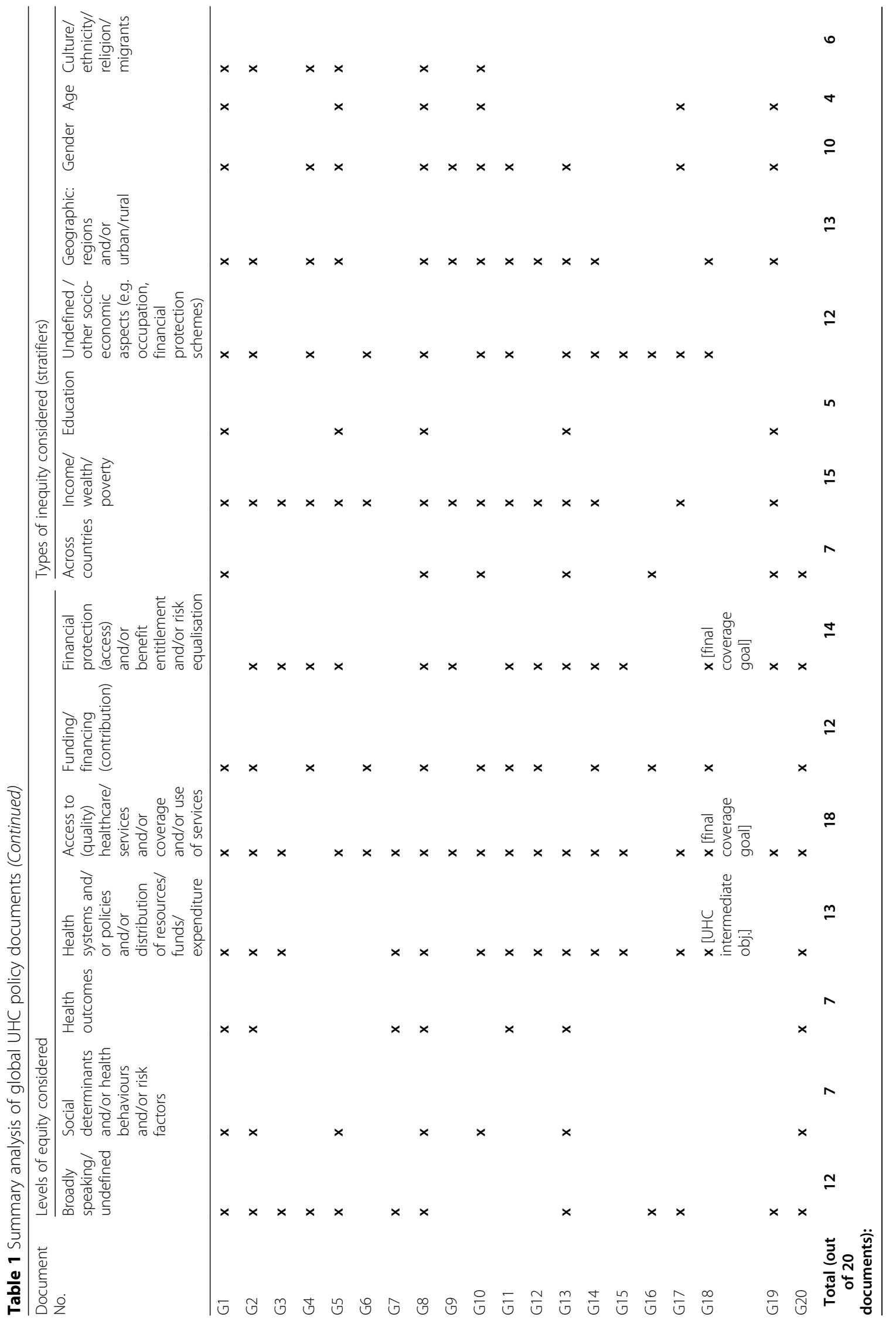




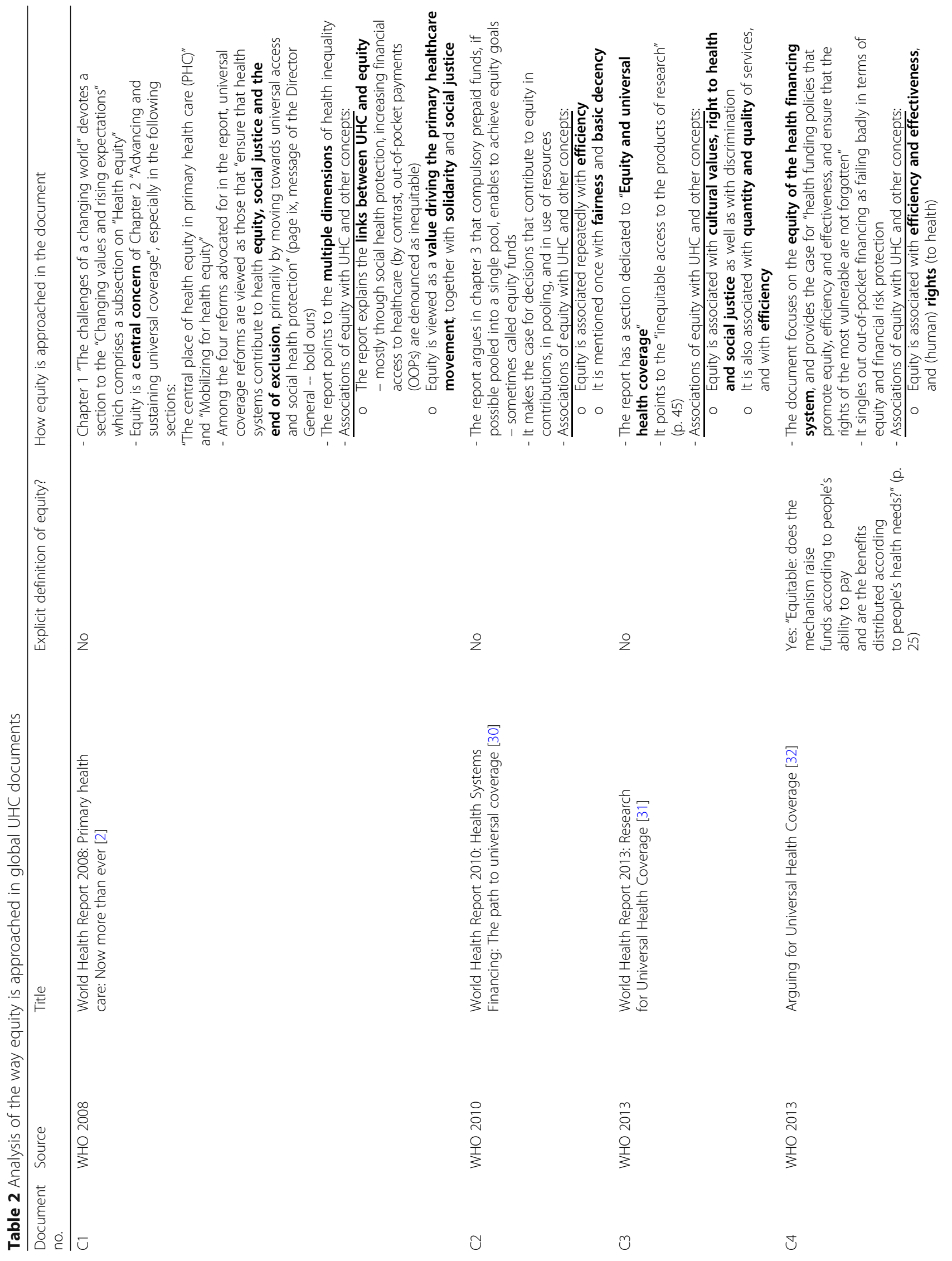




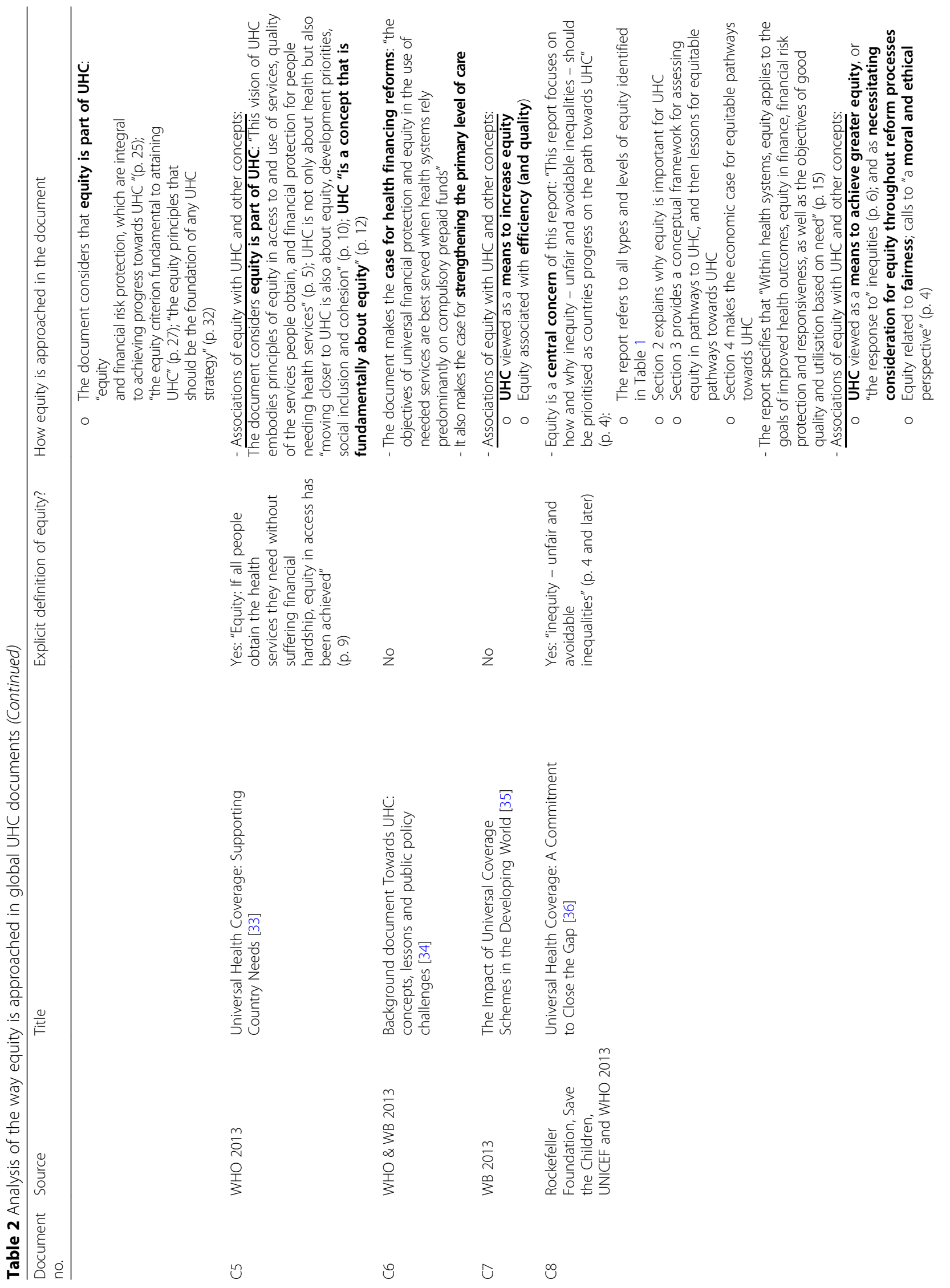




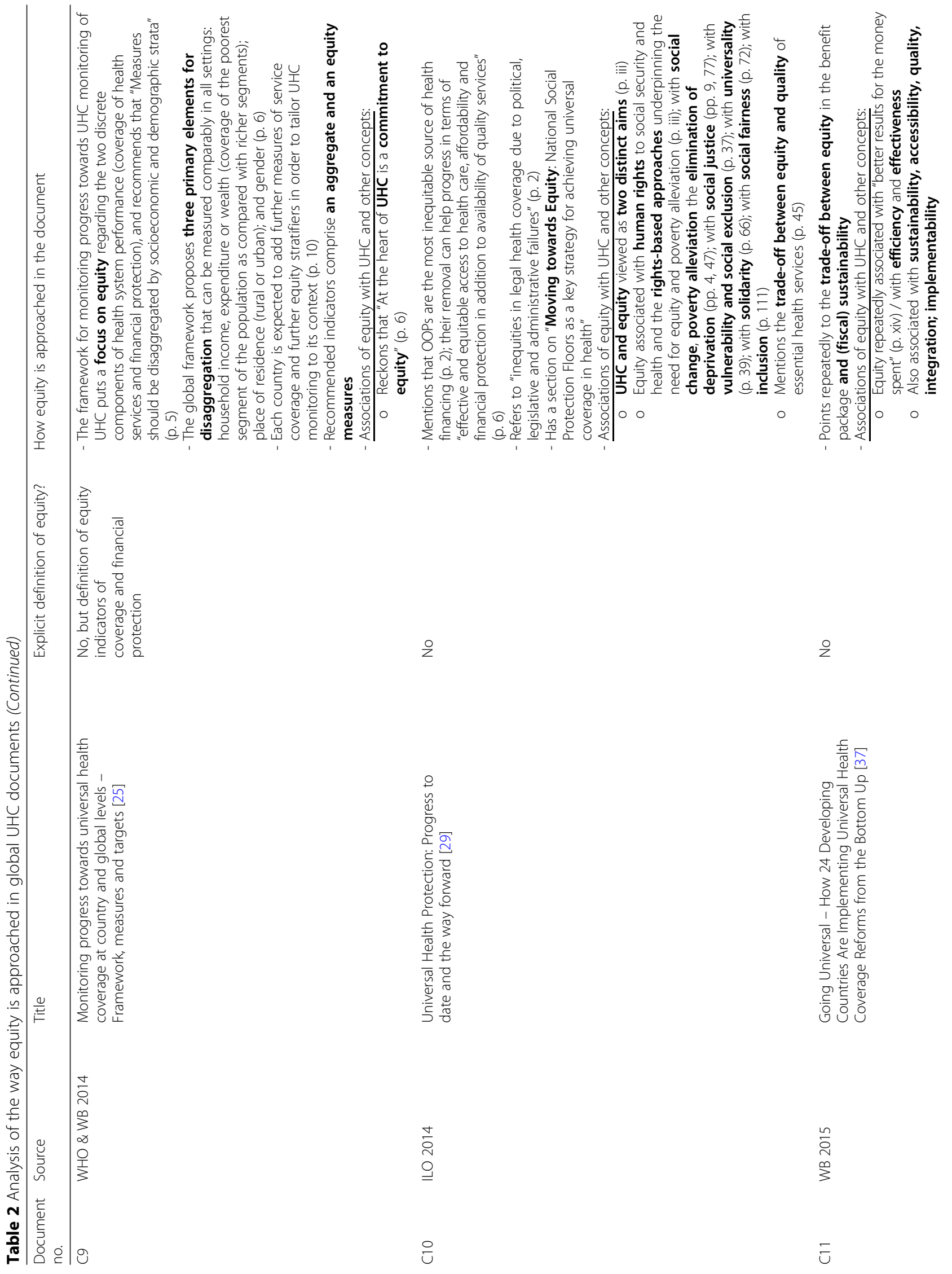




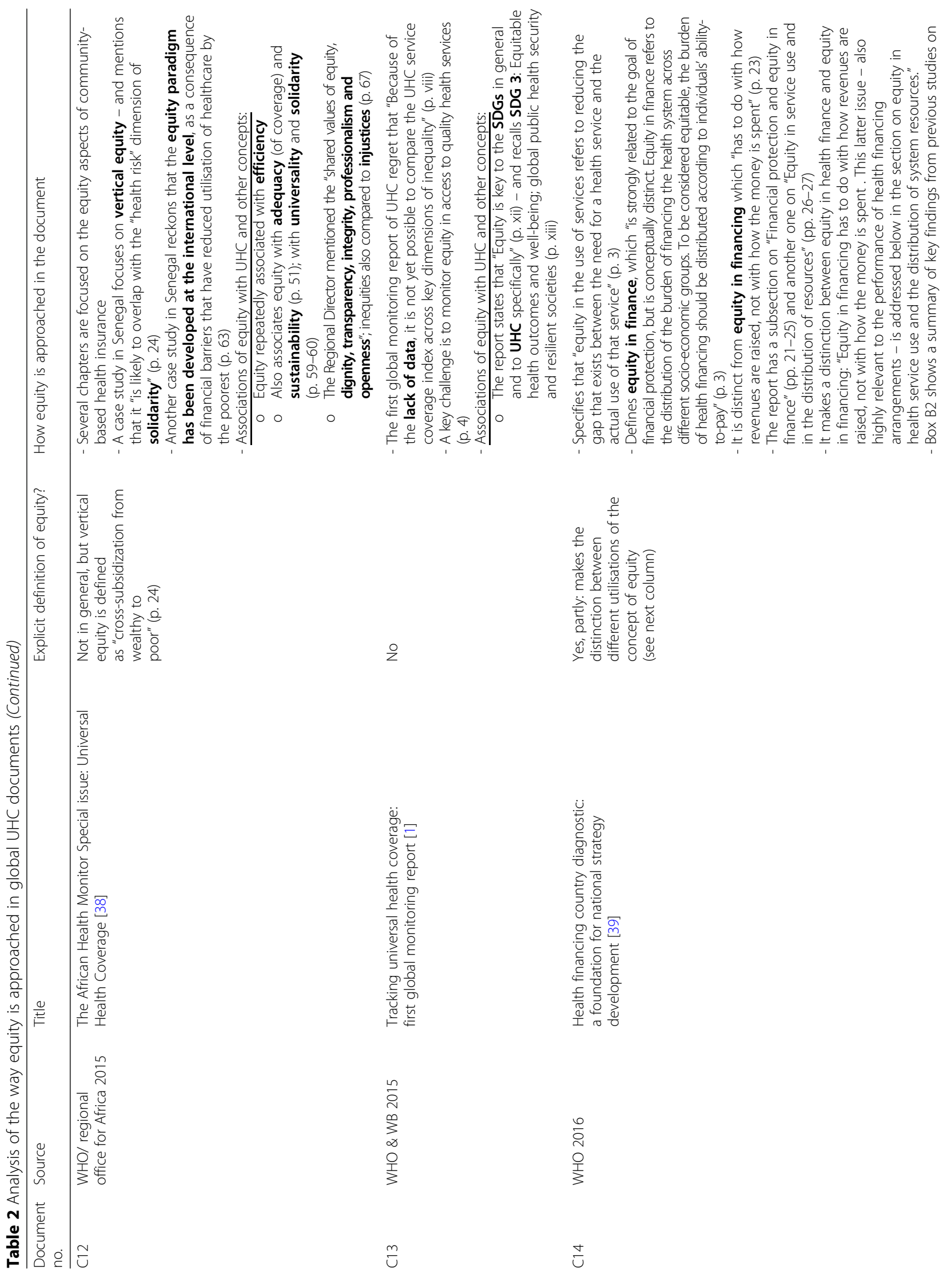




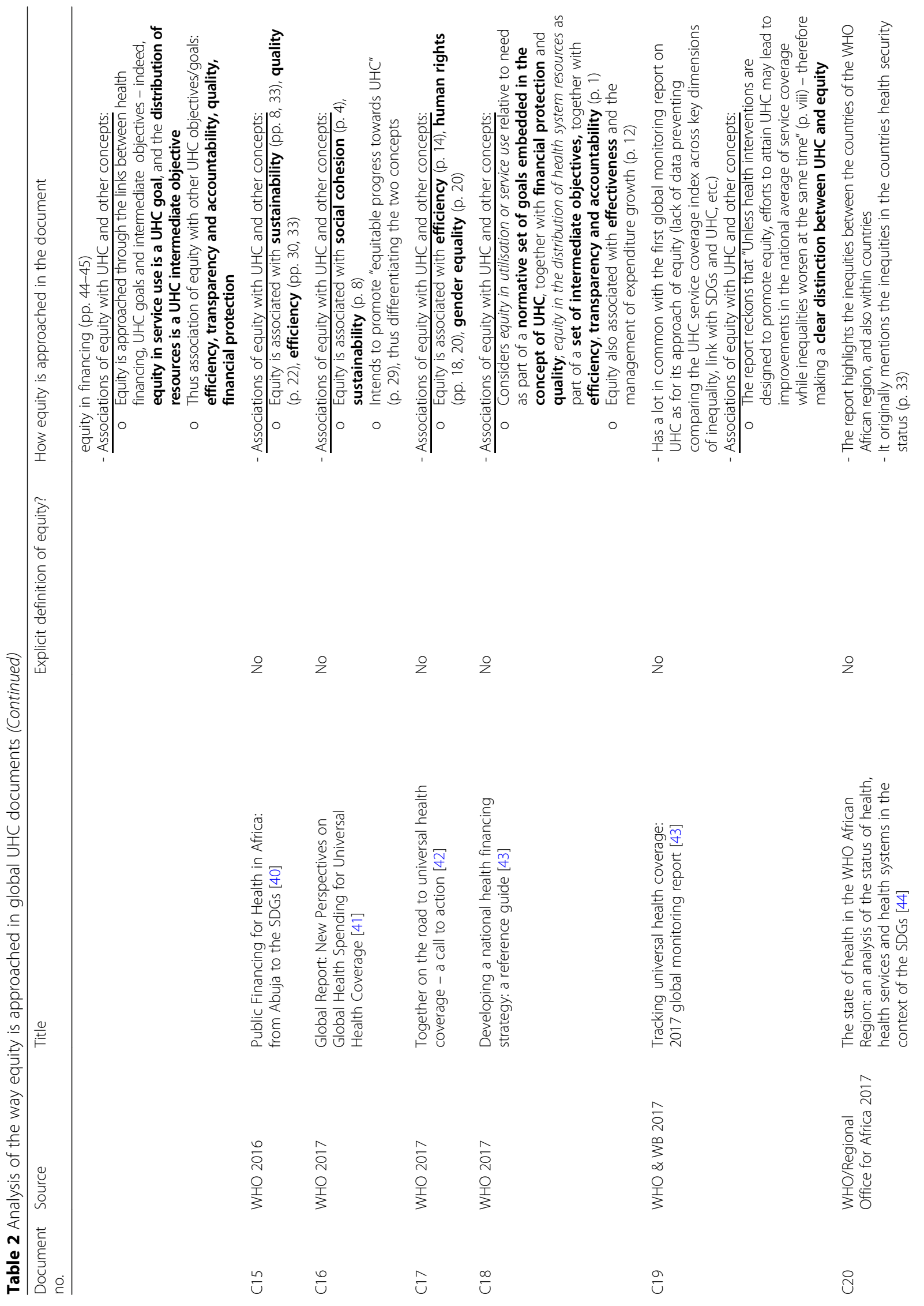




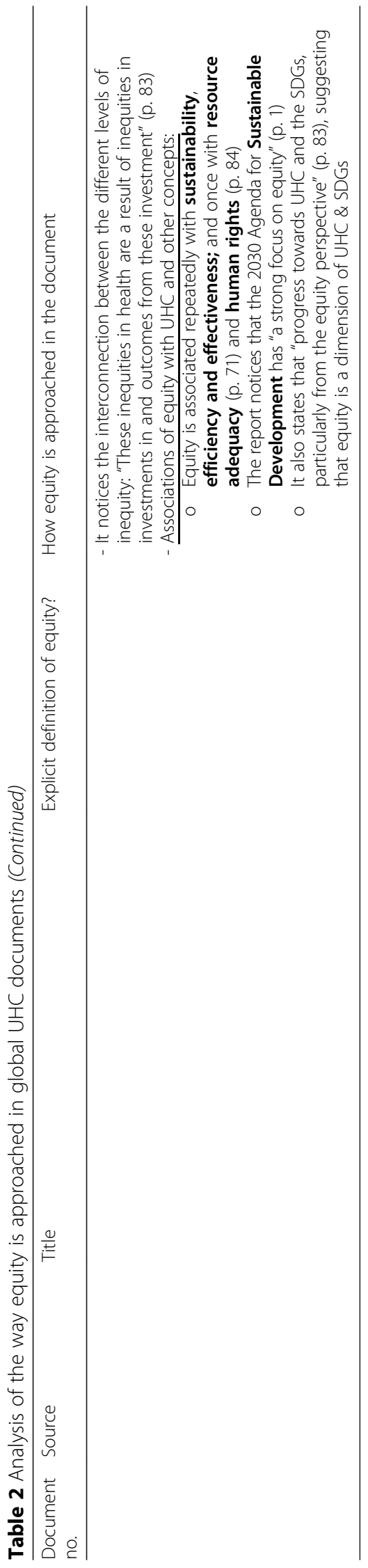




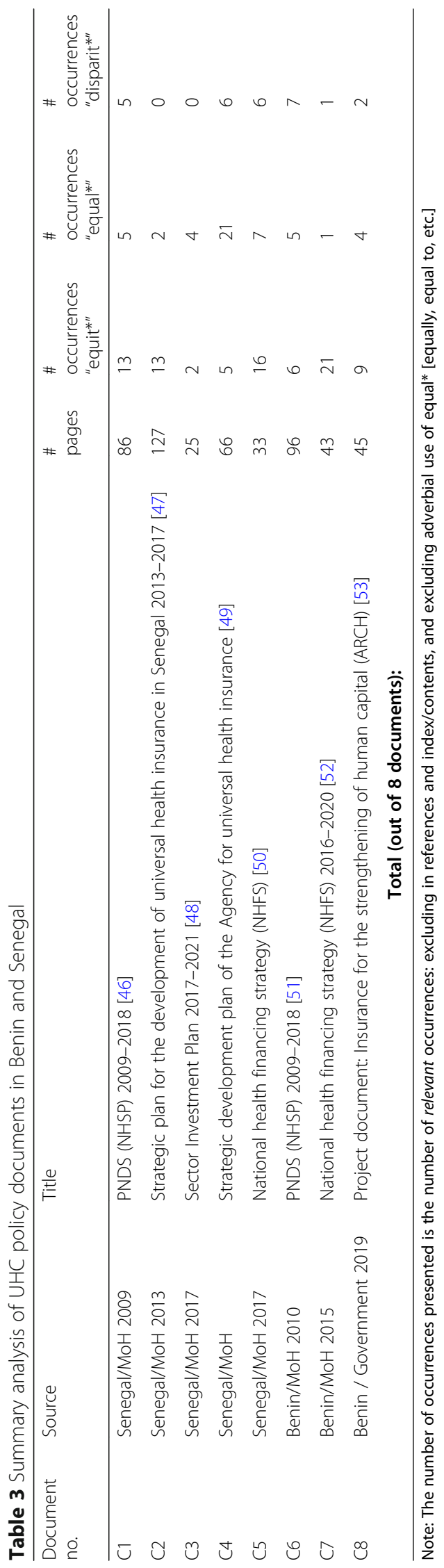




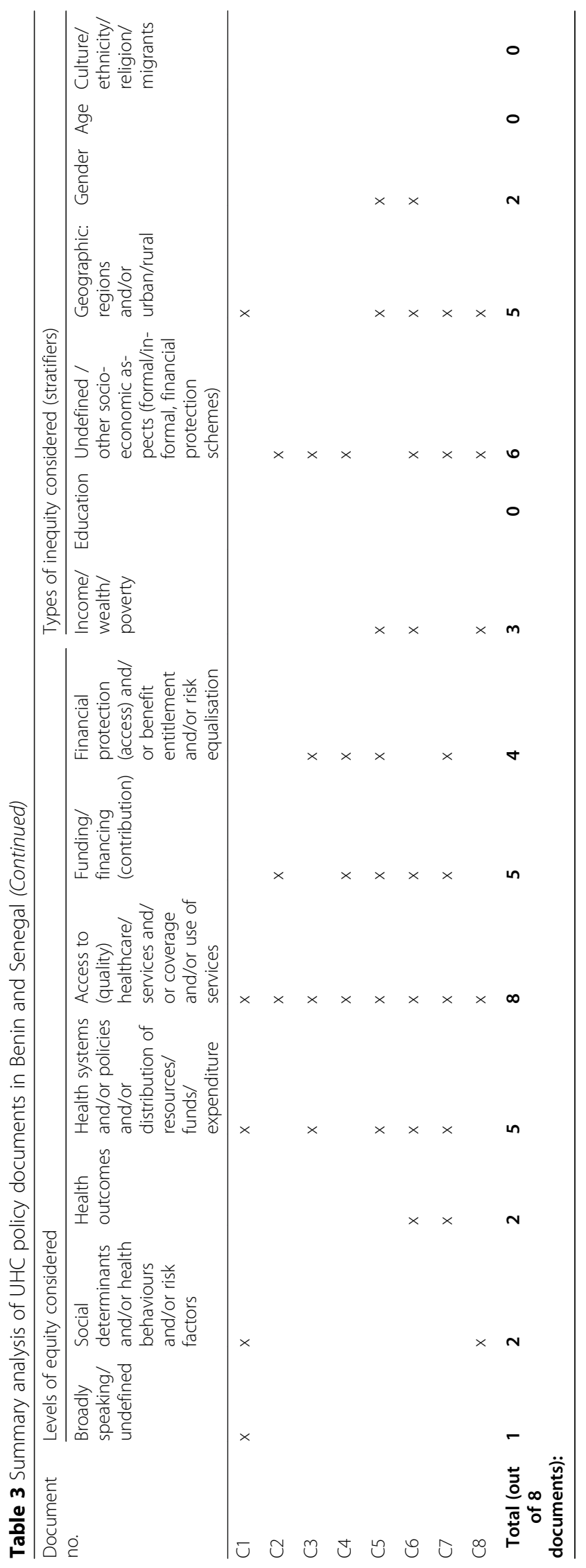




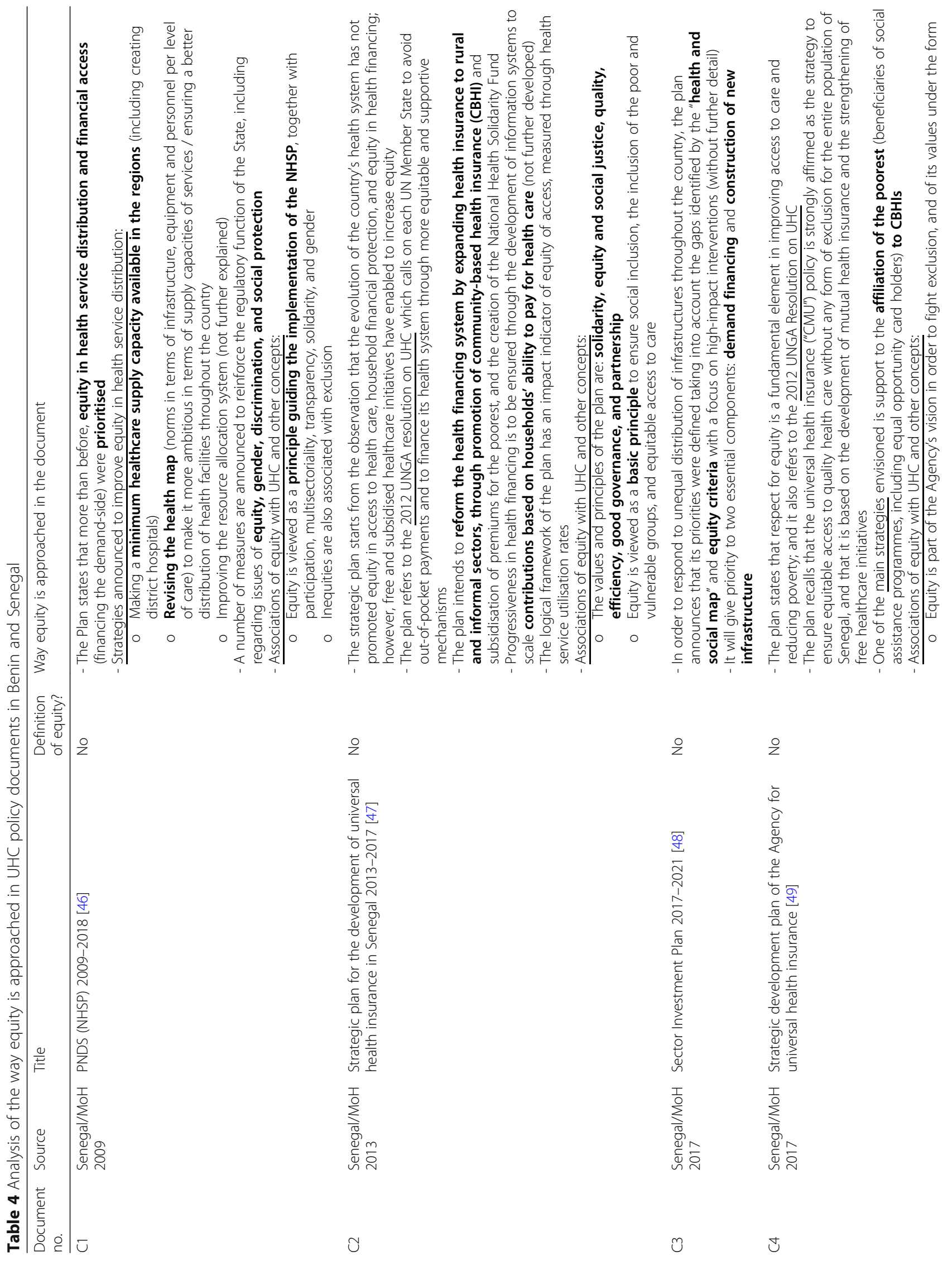




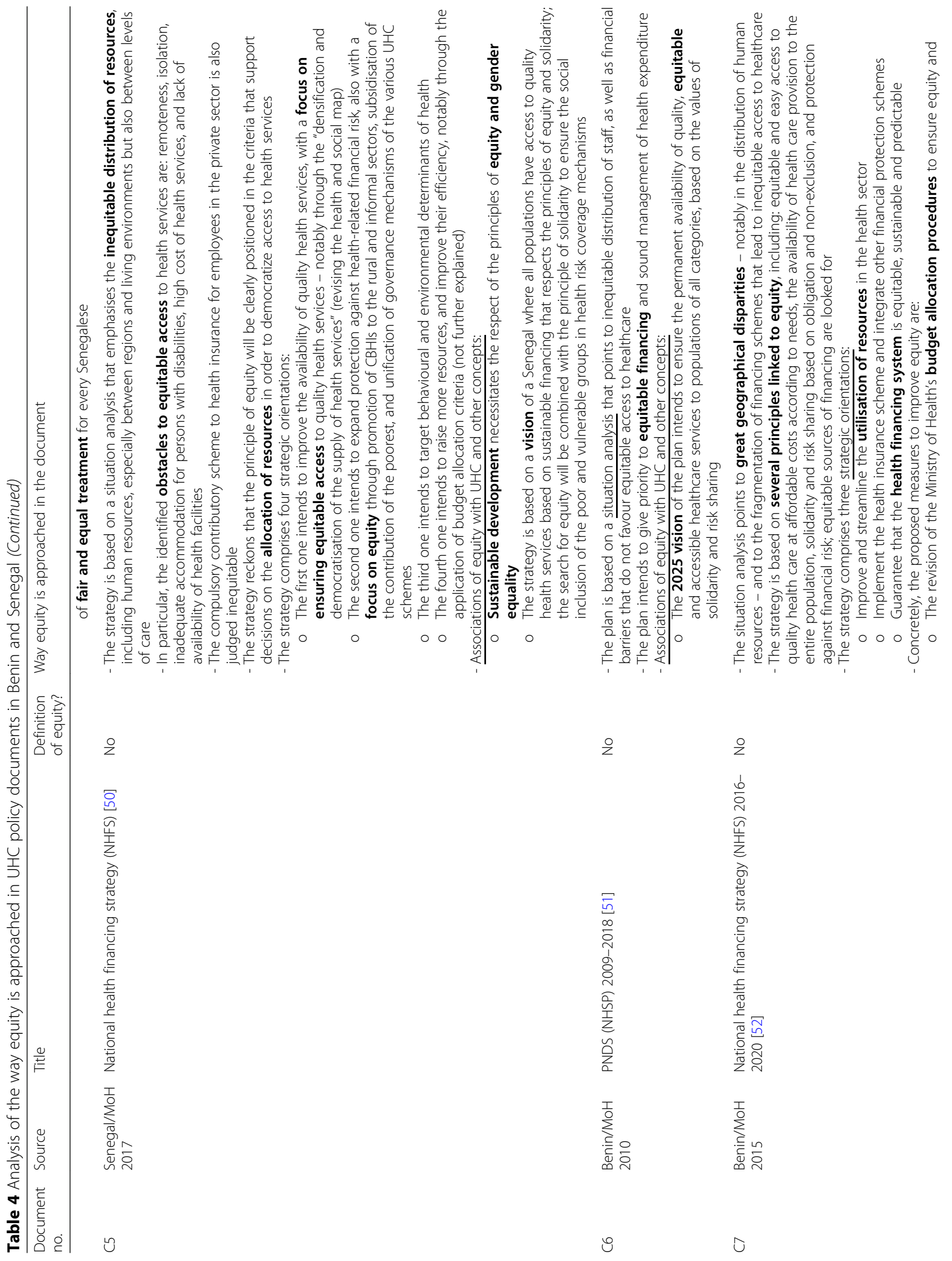




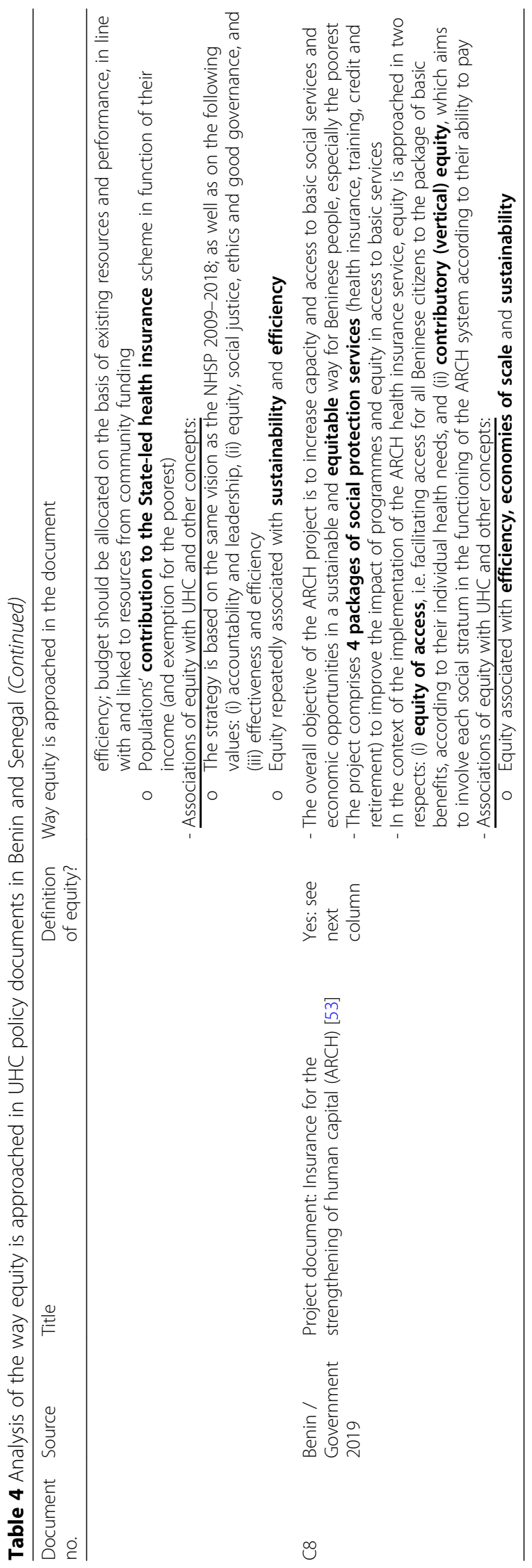


broad socio-economic disparities (e.g. formal vs. informal sector, vulnerable populations) are referred to by 6 documents out of 8 , while geographic (including rural/urban) inequalities are the most widely used explicit stratifier. However, in the documents reviewed, no mention was made to inequity in service quality or due to differences in education, age, or cultural aspects. Moreover, the examined country policy documents tend to refer to the principle of equity in a quite rhetoric way, in association with other broad concepts (e.g. solidarity, social justice) but also predominantly with efficiency and sustainability.

The supposedly predominant policy document in each country, that is the NHSP, covers the period 2009-2018 in both countries. The NHSP of Benin reckons the existence of inequitable distribution of staff, as well as financial barriers that do not favour equitable access to healthcare, and intends "give priority to equitable financing". It is based on a vision that intends to "ensure the permanent availability of quality, equitable and accessible healthcare services to populations of all categories, based on the values of solidarity and risk sharing" (our translation). However, no concrete measure to improve equity is proposed in the NHSP [51]. That of Senegal announces that "priority is given to the equitable distribution of the supply of services and the financing of health demand" and that "the provision of a minimum supply of care per region and the judicious spatial distribution of diagnostic and treatment facilities will ensure more equitable care"; this is presumed to be achieved through a "resource allocation system made more equitable" and a "greater attention given to the operationalisation of the health map" (our translation). If more concrete strategies to improve equity are indicated than in the one of Benin, the NHSP of Senegal also refers to equity in a vague, rhetoric way, as a guiding principle among others such as "participation, multisectoriality, transparency, solidarity, and gender" [46]. More concrete actions are to be found in the subsequent Sector Investment Plan that intends to "give priority to two essential components: demand financing and construction of new infrastructure" [48].

Both countries have also issued a national health financing strategy towards UHC (NHFS). That of Benin puts the emphasis on equity in financing and considers the need to "find places to collect (taxes, indirect taxes) that meet equity concerns" and to ensure "more equitable distribution of budget allocations" (our translation) [52]. That of Senegal diagnoses "an inequitable distribution of (human, material and financial) resources" (especially between regions and living environments, but also between levels of care) and states that "the principle of equity will be clearly positioned in the criteria that support decisions on the allocation of resources in order to democratise access to health services" (our translation). The strategy comprises four strategic orientations, the first two having a focus on equity in access to quality healthcare and financial protection [50]. However, beyond those principled statements, none of these plans proposes any concrete action (such as resource allocation criterion) to advance equity.

Finally, the two countries have chosen different strategies to increase financial protection coverage: while Senegal has opted for CBHIs [47, 49], Benin has opted for a State-led project, called $\mathrm{ARCH}$, which comprises for packages of social protection services (health insurance, training, credit and retirement) [53].

Overall, despite differences in contexts and in political choices and discourses, the UHC policies of the two countries are quite similar in terms of their approach to equity. Both countries acknowledge important health disparities especially geographic ones - and assign them to inequities in resource allocations and on insufficient financial protection. On the supply side, both countries intend to revise budget allocation procedures to ensure equity and efficiency - yet, the documents examined for Benin do not explain how to do so, while the UHC policy documents in Senegal mention the "health map" (i.e., the norms in terms of infrastructure, equipment and personnel per level of care) as a concrete way to do it $[46,48,50]$. On the demand side, both countries intend to increase financial health coverage by promoting a health insurance scheme for the rural and informal sectors, and subsidising the contributions of the poor to those schemes. They also recognise the problems arising from the fragmentation of financing schemes and consider setting up a common pool, but have not yet succeeded in this respect $[47,52]$. Finally, both countries are aware of the importance of social determinants of health; Senegal intends to act in this respect through multisectorial action, while Benin has rather opted for developing a whole package of social protection programmes through the ARCH project $[50,53]$.

\section{Discussion}

Our study has a number of methodological limitations. It is based mostly on a documentary review, and on a purposeful sample of reports and documents. We have deliberately excluded documents targeted on equity so as to appraise whether non-specific UHC documents apprehended this concept. We have based our analysis mostly on the documentary review, without complementary methods other than our personal knowledge and expertise, accumulated during our four-year research project and prior experience in the two focus countries. We have not analysed how these documents were produced, but their origin and formulation process could explain whether or not equity is taken into account.

Our results show that the concept of equity is often used in an imprecise and even rhetoric manner, both in global and in country-specific UHC policy documents. 
This is true both with respect to the levels of equity considered (access, coverage and use are often used interchangeably) and to the types of equity considered (with often undefined "socio-economic" disparities). Financial equity is particularly misunderstood in many documents under review: most examined documents confuse equity in resource mobilisation and equity in resource allocation - while actually "[e]quity in financing has to do with how revenues are raised, not with how the money is spent" [39].

Our study was based on an analysis of policy documents - but beyond stated policies, there might be important policy-implementation gaps. Our experience in Benin and Senegal shows that the two countries struggle to improve resource allocation and to increase financial protection coverage. In Benin, after the notable failure of the attempt of the previous government to develop a national health insurance scheme, the current government's ARCH project has endured long delays before it started to be piloted in July 2019 [54]. In Senegal, at the end of December 2018, only 19\% of the total population benefitted from health risk coverage through $\mathrm{CBHI}$, against an objective of $26 \%$ [55]. According to the recent Global monitoring report, the UHC Service Coverage Index (SDG 3.8.1) was at 39.6 for Benin in 2017 (down from 40.2 in 2015) and at 45.4 for Senegal in 2017 (up from 43.8 in 2015) [56]. How can that be explained? Whereas equity is a central concept in public health (thus as the policy-making level in the health sector), it is not apprehensible as such by all disciplines, which may lead to some difficulties as for translating polices into practice. Indeed, before they can be implemented, policies have to be translated into legal and institutional frameworks. However, the notion of equity merely does not exist as such in law. In Common Law systems, the term "equity" refers to a particular set of doctrines and procedures involved with civil law, which complement the statutory laws, but with no real connection to the meaning used in public health. In civil law legal systems, equity does not exist as a concept, but is comprehended through other concepts such as equality and nondiscrimination, protection of minorities, minimum base, proportionality or ability to pay, or fiscal federalism. It can also be addressed through economic and fundamental social rights, including the right to health, which imply positive obligations on behalf of government. Yet, the choice of the legal concept that will be used to translate the equity goal will not be without consequence.

Since equity encompasses many dimensions, a number of questions arise when aiming to increase equity in the context of UHC policies. First, which aspects of equity should be prioritised? For instance, should UHC policies guarantee basic rights to the whole population, or target the poorest (or other disadvantaged groups) first? A recent narrative review found that the majority of papers reviewed in public health found that UHC programmes should focus first on increasing coverage and decreasing economic barriers to access amongst the most disadvantaged groups ("progressive universalism") [9]. However, there is no consensus on how to realise that objective [57]. In particular, the implementation of targeted strategies (compared to universal ones) involve important pitfalls, such as the political unsustainability of the reforms, as well as the fact that "benefits meant exclusively for the poor often end up being poor benefits" [58]. Moreover, the levels and types of equity to be prioritised depend on the values of the society in which it takes place, and should logically vary from one country to another. Yet, we observe that while global documents consider many stratifiers, country-specific documents' diagnosis focuses on geographic and urban/rural inequities, which are probably the easiest type of disparities to be apprehended with existing data. Paradoxically, in the two countries under study, few concrete interventions are implemented to improve balance in the allocation of resources, while policies targeting the poorest or the most vulnerable exist for instance (e.g. free healthcare for children under five or caesarean sections, subsidisation of the ARCH social health insurance in Benin and adhesion to CBHI in Senegal). There is therefore a mismatch between the diagnosis of problems, and the solutions proposed. The urban bias in political decision in low- and middle-income countries has been known for decades [59]. Domestic political interests may probably explain why the health insurance policy are high in the political agenda of the Presidents of both Benin and Senegal. In Benin, the integrated social protection programme is designed to strengthen the human capital of the country in view of supporting its development, in line with the neoliberal vision of its government [53]. In Senegal, the choice of the CBHI model - against the tide of the international experience pointing to its limited potential to progress towards UHC [60] - was influenced by domestic mutualist lobbies supported by the American cooperation agency [61].

Second, once the equity objective has been defined, the question arises how to translate it into the country legal and institutional frameworks? Many alternatives may be possible in this respect, but the similarities in terms of equity objectives between the two studied countries - which have however chosen very different paths to reach UHC - raises questions about the capacity of countries to actually translate global guidelines into practice in a context-specific way. The question of how to translate a moral imperative into practice has been questioned for decades, as testified by the tensions around whether and how to provide "equal opportunity" 
in society [62]. The development of a UHC policy may be a strictly political agenda, but it may also be pushed back by constitutional or statutory constraints, international agreements or conventions; the UHC policy may have various degrees of binding forces - the right to health may be inscribed up to the level of the constitution (in which case it creates positive obligations for the state to secure the effective enjoyment of it). More generally, social rights and the right to health may have different legal values; if there is a legally binding commitment towards UHC, citizens could claim it directly or indirectly before the authorities, especially the courts. The stand-still rule (meaning that when a certain level of social protection or a right is reached, there is no turning back) may be used to guarantee financial commitments. Beyond access, equity in finance should also be searched for, implying that the distribution of the burden of financing health services is "fair", thus referring to the extent to which financing is progressive or regressive i.e. whether the burden falls disproportionately on the better-off, or worse-off, in society, relative to their capacity to contribute [63]. As outlined above, the two countries studied intend to render health financing more progressive and to pool resources at a high level, but no major progress has been achieved so far. In Benin, there is still no clear and sustainable mechanisms in place to finance the ARCH project [64]. In Senegal, the legal and institutional frameworks are not totally in line with the UHC policy [65].

Third, once formalised, how should the implementation of equity policies be facilitated? Once again, policies could be seductive but difficult to translate into appropriate decrees then implemented, be it for political or technical reasons [57], so wide policy-implementation gaps may take place [66]. Thus the content of policy documents does not necessarily reflect what is done in the field. The two country-specific cases suggest this is likely to happen as they put emphasis on re-equilibrating resource allocation within the health system, without defining allocation criteria or proposing any firm commitment to it - except for the reference to the health map in Senegal. Furthermore, during implementation, UHC policies should be closely monitored since they may have unexpected effects on equity. For instance, a recent study on maternal healthcare in Senegal shows that while a demand-side intervention (abolition of user fees) benefitted the poorer households more, thereby reducing inequity, a supply-side intervention (expansion of the availability of maternal health services) benefitted the richer households more, thereby increasing inequity [67].

Finally, it is worth remarking that improving equity in health necessitates intervention beyond the health sector, and beyond national frontiers. Indeed, UHC is not enough to ensure the right to health, and requires important changes to render the environment healthier [68]. Besides, national policies which target only domestic factors have limited ability to address health inequities, without engaging with the global political economy and acting on global health inequity determinants [69].

\section{Conclusion}

Overall, it appears from our study that while equity is widely referred to in global and country-specific UHC policy documents and seems self-evident, its context-specific interpretations and applications may vary, and the concept is often utilised in a rather rhetoric and/or political way. Whereas the concept of equity covers many levels and types, and except for very specific ones, many global UHC documents fail to define it properly and to comprehend the breadth of the concept. Consequently, perhaps, country-specific policy documents also take it for granted and use equity as a broad principle, without defining it properly and without proposing concrete ways to implement it. In the two countries under study, while UHC policy documents recognise the need to tackle geographic disparities, they actually fail to define binding rules to allocate resources (financial, human, material) in a more equitable way. As for policies aimed at protecting the poorest or the most vulnerable, they are either untargeted (e.g. all children under five or all pregnant women, whatever their socioeconomic status) or face difficulties in identifying the target population (the poorest) [71, 72]. An explanation may be found in the lack of tools that comprehend other types of inequities. Incidentally, "The use of facility data or other administrative sources presents challenges as they [...] typically do not collect variables relevant for equity analyses other than geographical location" [43]. Henceforth, collecting routine data disaggregated on the basis of other stratifiers could be a first step in taking better account of equity in UHC policies, and to better target populations most in need of special care. This would contribute to rendering the UHC policies more effective and more sustainable. In any case, only strong collaboration between policymakers, social scientists, financiers and lawyers can tailor UHC policies to specific country needs, and help translate them into institutional frameworks to facilitate their implementation.

\section{Abbreviations}

ARCH: Assurance pour le renforcement du capital humain (Benin); CBHI: Community-based health insurance; ILO: International Labour Organisation; MoH: Ministry of Health; NHFS: National health financing strategies; NHSP: National health sector plan; PNDS: Plan national de développement sanitaire (NHSP); SDGs: Sustainable Development Goals; UHC: Universal health coverage; WB: World Bank; WHO: World Health Organisation

Acknowledgements

We thank the Wallonia-Brussels Federation for the ARC funding. 


\section{Authors' contributions}

EP analysed the documents and wrote the first draft of the paper. All authors contributed to the design of the study, approved the selection of the documents reviewed, contributed to the analysis and gave their consent on the final draft.

\section{Funding}

The research was funded through the ARC grant for Concerted Research Actions, financed by the Wallonia-Brussels Federation.

\section{Availability of data and materials}

The documents reviewed are public.

\section{Ethics approval and consent to participate} Not relevant.

\section{Consent for publication}

Not relevant.

\section{Competing interests}

We declare we have no competing interests.

\section{Author details}

'Université de Liège, Faculty of Social Sciences, Place des Orateurs 3, 4000 Liège, Belgium. ${ }^{2}$ Université libre de Bruxelles, School of Public Health, Campus Erasme, Route de Lennik 808, 1070 Brussels, CP 591, Belgium. ${ }^{3}$ Université de Parakou, Faculté des lettres, arts et sciences humaines (FLASH) et Laboratoire de recherches sur les dynamiques sociales et le développement local (Lasdel), Parakou, Benin. ${ }^{4}$ University of Thiès, Research Center in Economics and Applied Finance (CREFAT), Thiès, Senegal. ${ }^{5}$ Université de Liège, Faculty of Law, Political Science and Criminology, and Tax Institute, Place des Orateurs 3, 4000 Liège, Belgium. ${ }^{6}$ IRD (French Institute for Research on Sustainable Development), CEPED (IRD-Université de Paris), Universités de Paris, ERL INSERM SAGESUD, 45 rue des Saints Pères, 75006 Paris, France.

\section{Received: 18 July 2019 Accepted: 12 November 2019}

\section{Published online: 17 December 2019}

\section{References}

1. World Health Organization. Tracking universal health coverage: first global monitoring report. Geneva, Switzerland: World Health Organization; 2015.

2. World Health Organization. World Health Organization (WHO). Primary Health Care: Now More than Ever, The World Health Report 2008. [Internet]. World Health Organization; 2008 [cited 2017 Nov 13]. Available from: http:// www.who.int/whr/2008/en/

3. Kutzin J. Health financing for universal coverage and health system performance: concepts and implications for policy. Bull World Health Organ. 2013;91(8):602-11.

4. World Health Organization. Making fair choices on the path to universal health coverage. Final report of the WHO Consultative Group on Equity and Universal Health Coverage [Internet]. World Health Organization; 2014 [cited 2017 Nov 13]. Available from: http://www.who.int/choice/documents/ making_fair_choices/en/

5. O'Connell T, Rasanathan K, Chopra M. What does universal health coverage mean? Lancet Lond Engl. 2014;383(9913):277-9.

6. Norheim OF. Ethical perspective: five unacceptable trade-offs on the path to universal health coverage. Int J Health Policy Manag. 2015;4(11):711-4.

7. Umeh CA, Feeley FG. Inequitable access to health care by the poor in community-based health insurance programs: a review of studies from lowand middle-income countries. Glob Health Sci Pract. 2017;5(2):299-314.

8. Fenny AP, Yates R, Thompson R. Social health insurance schemes in Africa leave out the poor. Int Health. 2018;10(1):1-3.

9. Rodney AM, Hill PS. Achieving equity within universal health coverage: a narrative review of progress and resources for measuring success. Int J Equity Health. 2014;13:72

10. Roberts MJ, Hsiao WC, Reich MR. Disaggregating the universal coverage cube: putting equity in the picture. Health Syst Reform. 2015;1(1):22-7.

11. Braveman P. What are health disparities and health equity? We need to be clear. Public Health Rep Wash DC 1974. 2014;129 Suppl 2 (Suppl 2):5-8
12. Wagstaff A, van Doorslaer E, Paci P. Equity in the finance and delivery of healthcare: some tentative cross-country comparisons. Oxf Rev Econ Policy. 1989;5(1):89-112.

13. Cohen $A B$, Grogan $C M$, Horwitt JN. The many roads toward achieving health equity. J Health Polit Policy Law. 2017;42(5):739-48.

14. Potvin L, Mantoura P, Ridde V. Evaluating equity in health promotion. Global Perspectives on Health Promotion Effectiveness. Springer. McQueen D.V., Jones C.M: In; 2007

15. Mclntyre D, Mooney G. Where now with equity? In: Mclntyre D, Mooney G, editors. The economics of health equity [internet]. Cambridge: Cambridge University Press; 2007. p. 249-68. Available from: https://www.cambridge. org/core/books/economics-of-health-equity/where-now-with-equity/F08F2 F5CB4DEE82E1576DF486B1BFF58.

16. Whitehead $M$. The concepts and principles of equity and health. Int J Health Serv Plan Adm Eval. 1992:22(3):429-45.

17. Commission on Social Determinants of Health. Closing the gap in a generation: Health equity through action on the social determinants of health. Geneva: World Health Organization; 2008.

18. Braveman PA. Health disparities and health equity: concepts and measurement. Annu Rev Public Health. 2006;27:167-94.

19. Braveman PA, Kumanyika S, Fielding J, LaVeist T, Borrell LN, Manderscheid R, et al. Health disparities and health equity: the issue is justice. Am J Public Health. 2011;101(S1):S149-55.

20. O'Connell TS, Bedford KJA, Thiede M, McIntyre D. Synthesizing qualitative and quantitative evidence on non-financial access barriers: implications for assessment at the district level. Int J Equity Health. 2015;14:54.

21. Hall M, Graffunder C, Metzler M. Policy approaches to advancing health equity. J Public Health Manag Pract. 2016;22:S50-9.

22. Wagstaff $A$, Paci $P$, van Doorslaer $E$. On the measurement of inequalities in health. Soc Sci Med. 1991;33(5):545-57.

23. O'Donnell O, van Doorslaer E, Wagstaff A, Lindelow M. Analyzing Health Equity Using Household Survey Data : A Guide to Techniques and Their Implementation [Internet]. Washington DC: The World Bank; 2008. Available from: https://openknowledge.worldbank.org/handle/10986/6896 License: CC BY $3.0 \mathrm{IGO}$.

24. Hosseinpoor AR, Bergen N, Koller T, Prasad A, Schlotheuber A, Valentine N, et al. Equity-oriented monitoring in the context of universal health coverage. PLoS Med. 2014;11(9):e1001727.

25. World Health Organization, World Bank. Monitoring progress towards universal health coverage at country and global levels - Framework measures and targets. 2014 May.

26. Deville C. Same objective, different paths : An analysis of Universal Health Coverage policies in Benin and Senegal. International Conference on Global Dynamics of Social Policy Social policy dynamics in (West and Central) Africa; 2018 Oct 25; University of Bremen.

27. Jordan K, Marten R, Gureje O, Daelmans B, Kruk ME. Where is quality in health systems policy? An analysis of global policy documents. Lancet Glob Health. 2018;6(11):e1158-61.

28. Wagstaff A, Eozenou P, Neelsen S, Smitz M. The 2018 health equity and financial protection indicators database - overview and insights. World Bank Group; 2018.

29. Scheil-Adlung X. Universal Health Protection: Progress to date and the way forward. Social Protection Policy Papers, Paper 10. International Labour Organization (ILO); 2014

30. World Health Organization. Health Systems Financing - The Path to Universal Coverage, The World Health Report 2010 [Internet]. World Health Organization; 2010 [cited 2017 Nov 13]. Available from: http://www.who.int/whr/2010/en/

31. World Health Organization. World Health Report 2013: Research for Universal Health Coverage. Geneva, Switzerland; 2013.

32. World Health Organization. Arguing for universal health coverage. Geneva, Switzerland: World Health Organization; 2013.

33. World Health Organization. Universal Health Coverage: Supporting Country Needs. 2013.

34. World Health Organization and World Bank. WHOMorld Bank Ministerial-level Meeting on Universal Health Coverage 18-19 February 2013, WHO headquarters, Geneva, Switzerland. Report on the ministerial level roundtable on Universal Health Coverage [Internet]. Geneva: WHO/World Bank; 2013.

35. Giedion U, Alfonso EA, Diaz Y. The impact of universal coverage schemes in the developing world : a review of the existing evidence. Universal Health Coverage (UNICO) studies series ; no. 25 [Internet]. Washington D.C. : The World Bank; 2013 [cited 2017 Nov 13]. Available from: http://documents. 
worldbank.org/curated/en/349621468158382497/The-impact-of-universalcoverage-schemes-in-the-developing-world-a-review-of-the-existing-evidence

36. Brearley L, Marten R, O'Connell T. Universal health coverage: a commitment to close the gap. New York: The Rockefeller Foundation, Save the Children, UNICEF and the World Health Organization; 2013.

37. Cotlear D, Nagpal S, Smith O, Tandon A, Cortez R. Going universal - how 24 developing countries are implementing universal health coverage reforms from the bottom up [internet]. Washington, DC: The World Bank; 2015 [cited 2017 Nov 13]. Available from: http://documents.worldbank.org/ curated/en/936881467992465464/pdf/99455-PUB-Box393200B-OUO-9PUBDATE-9-28-15-DOI-10-1596-978-1-4648-0610-0-EPI-210610.pdf

38. WHO/ regional office for Africa. The African Health Monitor Special issue: Universal Health Coverage. 2015.

39. McIntyre D, Kutzin J. Health financing country diagnostic: a foundation for national strategy development [Internet]. World Health Organization; 2016 [cited 2017 Dec 18]. Available from: http://www.who.int/iris/ handle/10665/204283

40. World Health Organization. Public Financing for Health in Africa: from Abuja to the SDGs. Geneva, Switzerland; 2016. Report No: WHO/HIS/HGF/Tech. Report/16.2.

41. World Health Organization. Global Report: New Perspectives on Global Health Spending for Universal Health Coverage. World Health Organization; 2017.

42. World Health Organization. Together on the road to universal health coverage: a call to action. Geneva, Switzerland: World Health Organization; 2017. Report No.: WHO/HIS/HGF/17.1

43. Kutzin J, Witter S, Jowett M, Bayarsaikhan D. Developing a national health financing strategy: a reference guide. Health financing guidance series no 3. World health Organization. 2017

44. World Health Organization, World Bank. 2017;2017.

45. WHO Regional Office for Africa. The state of health in the WHO African region: an analysis of the status of health, health services and health systems in the context of the sustainable development goals. Brazzaville: world health Organization; 2018.

46. République du Sénégal, Ministère de la santé et de la prévention. Plan national de développement sanitaire PNDS 2009-2018. 2009.

47. Ministère de la Santé et de l'Action sociale. Plan stratégique de développement de la Couverture Maladie Universelle au Sénégal 2013-2017. 2013.

48. République du Sénégal Ministère de la Santé et de l'Action sociale. Programme d'investissements sectoriels 2017-2021. 2017.

49. Ministère de la Santé et de l'Action sociale, Agence de la Couverture Maladie Universelle. Plan stratégique de développement de l'Agence de la Couverture Maladie Universelle 2017-2021. 2017.

50. République du Sénégal, Ministère de la Santé et de l'Action sociale (MSAS). Stratégie nationale de financement de la santé (SNFS) pour tendre vers la couverture sanitaire universelle 2017.

51. République du Bénin, Ministère de la Santé. Plan national de développement sanitaire 2009-2018. 2010.

52. Ministère de la Santé. Stratégie Nationale de Financement de la Santé pour la Couverture sanitaire Universelle du Bénin 2016-2022 (SNFS). 2015.

53. Présidence de la République du Bénin. Assurance pour le Renforcement du Capital Humain (ARCH). Fiche de projet 2017.

54. Deville C, Fecher F, Poncelet M. L'Assurance pour le renforcement du capital humain (ARCH) au Bénin : processus d'élaboration et défis de mise en œuvre. Rev Fr Aff Soc. 2018;1:107-23.

55. Agence de la Couverture Maladie Universelle, Direction de l'Assurance maladie. Rapport de performance de l'année 2018. Ministère de la Santé et de l'Action sociale; 2019 Jan.

56. World Health Organization. Primary Health Care on the Road to Universal Health Coverage (conference edition). World Health Organization; 2019.

57. Paul E, Fecher F, Meloni R, van Lerberghe W. Universal health coverage in francophone sub-Saharan Africa: assessment of Global Health experts' confidence in policy options. Glob Health Sci Pract. 2018;6(2):260.

58. Sen A. The Political Economy of Targeting. In: Public Spending and the Poor: Theory and Evidence [Internet]. Johns Hopkins University Press for the World Bank. Baltimore, MD: van de Walle, Dominique, and Kimberly Nead; 1995. p. 11-24. Available from: documents.worldbank.org/curated/en/404 991468778782212/pdf/multiopage.pdf.

59. Lipton M. Why poor people stay poor: urban Bias in world development Cambridge, MA: Harvard University Press; 1977

60. Mathauer L, Mathivet B, Kutzin J. Community based health insurance: How can it contribute to progress towards UHC? Health Financing Policy Brief No
3 [Internet]. World Health Organization; 2017 [cited 2017 Nov 13]. Available from: http://apps.who.int/iris/bitstream/10665/255629/1/WHO-HIS-HGFPolicyBrief-17.3-eng.pdf?ua=1

61. Caffin J-H. L'aide au développement et le financement basé sur la performance : quelle performativité ? Analyse du processus de conceptualisation et de diffusion du financement basé sur la performance dans la gestion des systèmes de santé africains par la Banque Mondiale et I'USAID. Etude du cas du Programme national de financement basé sur les résultats du Ministère de la Santé du Sénégal. [Paris]: Ecole Doctorale de Management Panthéon-Sorbonne; 2018.

62. Rawls J. Justice as fairness: a restatement. Kelly: Belknap Press. Erin L; 2001.

63. Jowett M, Kutzin J. Raising revenues for health in support of UHC: strategic issues for policy makers. Health Financing Policy Brief $\mathrm{n}^{\circ} 1$, WHO/HIS/HGF/ PolicyBrief/15.1 [Internet]. World Health Organization; 2015 [cited 2017 Nov 13]. Available from: http://apps.who.int/iris/bitstream/10665/192280/1/ WHO_HIS_HGF_PolicyBrief_15.1_eng.pdf?ua=1

64. Paul E, Sambieni NE, Wangbe J-P, Fecher F, Bourgeois M. Fiscal challenges on the path towards universal health coverage: the case of Benin. Mimeo, University of Liege; 2019

65. Badiane M-C, Bourgeois M, Dioh A. Financing Universal Health Coverage in Senegal: Why and how lawyers must be involved to reach the financing objectives. Mimeo, University of Saint-Louis (Senegal); 2018.

66. Ridde $\mathrm{V}$. 'The problem of the worst-off is dealt with after all other issues': the equity and health policy implementation gap in Burkina Faso. Soc Sci Med 1982. 2008 Mar;66(6):1368-78.

67. Parmar D, Banerjee A. How do supply- and demand-side interventions influence equity in healthcare utilisation? Evidence from maternal healthcare in Senegal Soc Sci Med. 2019;241:112582.

68. Ooms G, Brolan C, Eggermont N, Eide A, Flores W, Forman L, et al. Universal health coverage anchored in the right to health. Bull World Health Organ. 2013;91(1):2-2A.

69. McNamara CL. Relieving the tension between national health equity strategies and global health equity. Scand J Public Health. 2019;47(6):608-10.

70. Coady D, Grosh M, Hoddinott J. Targeting of transfers in developing countries : review of lessons and experience [lnternet]. The World Bank; 2004 [cited 2019 Jul 11]. Available from: http://documents.worldbank.org/ curated/en/464231468779449856/Targeting-of-transfers-in-developingcountries-review-of-lessons-and-experience

71. Deville C, Escot F, Ridde V, Touré L. Les processus d'identification des plus pauvres à l'épreuve du terrain : Une comparaison Bénin-Mali-Sénégal: In Roskilde University; 2018

72. Kutzin J, Witter S, Jowett M, Bayarsaikhan D. Developing a national health financing strategy: a reference guide. Health Financing Guidance no.3 [Internet]. World Health Organization; 2017 [cited 2017 Dec 18]. Available from: http://apps.who.int/iris/handle/10665/254757

\section{Publisher's Note}

Springer Nature remains neutral with regard to jurisdictional claims in published maps and institutional affiliations.

Ready to submit your research? Choose BMC and benefit from:

- fast, convenient online submission

- thorough peer review by experienced researchers in your field

- rapid publication on acceptance

- support for research data, including large and complex data types

- gold Open Access which fosters wider collaboration and increased citations

- maximum visibility for your research: over $100 \mathrm{M}$ website views per year

At $\mathrm{BMC}$, research is always in progress.

Learn more biomedcentral.com/submissions 